\title{
REPORT OF THE MEETING OF THE ASSOCIATION OF TEACHERS OF MATHEMATICS IN THE MTDDLE STATES AND MARYLAND.
}

The ninth meeting of the Association of Teachers of Mathematics in the Middle States and Maryland was held at the College of the City of New York, Saturday, November 30. President Einley delivered an entertaining and cordial address of welcome, which was responded to by the president of the association.

The following amendment to the constitution was carried:

(To separate the offices, Secretary and Treasurer)

Section III. To be amended to read :

The officers of this Association shall be a President, a Vice President, a Secretary, and a Treasurer. These four officers with six additional members shall form the Council. The President, Vice President, Secretary, and Treasurer shall be elected - - (without further change).

Professor Legras then presented a preliminary report for the Committee on Algebra syllabus. It was reported that the committee had not yet agreed on the exact topics and amount to be taught in the first year of algebra, though some conclusions had been arrived at. It bad been decided to exclude cube root from the High School work, and to leave inequalities for the second year. The committee asked for further time to consider the subject, and presented a printed list of topics, asking members of the association to suggest as to which should be taken up in the first year of algebra. This report aroused sharp discussion, and the committee was continued.

The first paper was by Charles D. Meserve, President of the New England Association of Mathematics Teachers. This paper was especially timely, as the two associations have recently decided to publish a joint bulletin, instead of separate publications. Dr. Meserve discussed the aims and progress of the New England Association, emphasizing especially its geometry syllabus, which has been very widely approved and adopted. He spoke very highly of the syllabus method of teaching mathematics.

In the afternoon, Eugene R. Smith of the Montclair High School discussed "The Coördinate Method as Applied to Plane Trigonometry." Mr. Smith said, among other things, that a function of an angle in the second, third, or fourth quadrant was negative if it contained, respectively, the abscissa, distance, or ordinate; and showed that this fact might be made the basis of all transformations of functions of angles in the form $N \pi \pm A$ to functions of $A$.

George Alvin Snook of Philadelphia Central High School spoke on "Geometry and Algebra for Knowledge or Power?" Mr. Snook took the position that pupils may acquire a great deal of power from the proper training of their mathematical faculties, and that the necessary facts can easily be acquired at the same time. He believed that certain of the methods of elementary algebra and some geometry theorems were beyond the pupils' original ability, and so needed development by the teacher and a receptive mind on the part of the pupil, but that many 
sippi the production of hardwoods is elearly at its extreme height, and In Missouri and Texas it has already begun to decline.

other parts of the elementary work could be used as subjects for investigation and for acquirement of power. In the discussion of this paper wide differences of opinion as to the ability of pupils to do original work were shown. These opinions ranged from those who believed that pupils properly trained and guided could do a large share of the elementary work from an investigational standpoint, to those who believed pupils capable of little or nothing in this line. As a rule the speakers were optimistic as to the ability of the pupils.

The last paper of the day was an illustrated lecture on "Modern Calculating Machinery," by Profiessor Clifford B. Upton of Teachers' College. Professor Upton showed pictures of the various kinds of calculating machines, and gave a very clear and interesting discussion of their mechanism and use.

The following officers were elected for the coming year:

President, William Henry MaItbie, Woman's College of Baltimore.

Vice-President, William E. Breckenridge, Stuyvesant High School, New York City.

Secretary, Eugene Randolph Smith, Montclair High School, Mont clair, N. J.

Treasurer, Emma Hazleton Carroll, Girls' High School, Philadelphia, Pa.

Members of the Council, to serve until 1910, Arthur S. Gale, University of Rochester, John J. Quinn, Scottdale, Pa.

It was decided to hold the spring meeting of the association in Baltimore. The association has been invited to join the open meeting of the Association of Teachers of History in the Middle States and Maryland on the evening of March 13th, and the regular sessions will be held on March 14th.

The reports of the committees and officers showed the association to be in a flourishing condition. Seventy new members have been added during the year, and the five sections are all active and progressive.

EUGEne R. SMith, Secretary.

\section{USE OF THE DIVINING ROD.}

Numerous devices are used throughout this country for detecting the presence of underground water-devices ranging in complexity from the forked branch of witch-hazel, peach, or other wood, to more or less elaborate mechanical or electrical contrivances. Many of the operators of these devices, especially those that use the home-cut forked branch, are perfectly honest in the belief that the working of the rod is influenced by agencies-ustally regarded as electric currents following underground streams of water-that are entirely independent of their own bodies, and many uneducated people have implicit faith in their ability to locate underground water in this way.

In experiments with a rod of this type, one of the geologists of the United States Geological Survey found that at points it turned downward independently of his will, but more complete tests showed that the downturning resulted from slight and-until watched for-uncon- 